\title{
Range expansion in an invasive small mammal: influence of life-history and habitat quality
}

\author{
Thomas A. White • Mathieu G. Lundy • W. Ian Montgomery - Sally Montgomery • \\ Sarah E. Perkins • Colin Lawton · John M. Meehan · Tom J. Hayden · \\ Gerald Heckel $\cdot$ Neil Reid $\cdot$ Jeremy B. Searle
}

Received: 22 November 2011/Accepted: 9 April 2012/Published online: 18 April 2012

(C) Springer Science+Business Media B.V. 2012

\begin{abstract}
Invasive species pose a major threat to biodiversity but provide an opportunity to describe the processes that lead to changes in a species' range. The bank vole (Myodes glareolus) is an invasive rodent that was introduced to Ireland in the early twentieth century. Given its continuing range expansion, the substantial empirical data on its spread thus far, and the absence of any eradication program, the bank vole in Ireland represents a unique model system for studying the mechanisms influencing the rate of range expansion in invasive small mammals. We described the invasion using a reaction-diffusion model informed by empirical data on life history traits and
\end{abstract}

T. A. White $(\varangle) \cdot$ J. B. Searle

Department of Ecology and Evolutionary Biology, Cornell University, Corson Hall, Ithaca, NY 14853-2701, USA

e-mail: tawhite201@gmail.com

T. A. White - G. Heckel

CMPG Lab, Institute of Ecology and Evolution, University of Bern, Baltzerstrasse 6, 3012 Bern, Switzerland

M. G. Lundy · W. I. Montgomery

School of Biological Sciences, Queen's University Belfast, MBC, 97 Lisburn Road, Belfast BT9 7BL,

Northern Ireland, UK

\section{W. I. Montgomery · N. Reid}

Quercus, School of Biological Sciences, Queen's University Belfast, MBC, 97 Lisburn Road, Belfast BT9

7BL, Northern Ireland, UK demographic parameters. We subsequently modelled the processes involved in its range expansion using a rule-based spatially explicit simulation. Habitat suitability interacted with density-dependent parameters to influence dispersal, most notably the density at which local populations started to donate emigrating individuals, the number of dispersing individuals and the direction of dispersal. Whilst local habitat variability influenced the rate of spread, on a larger scale the invasion resembled a simple reaction-diffusion process. Our results suggest a Type 1 range expansion where the rate of expansion is generally constant over time, but with some evidence for a lag period

S. Montgomery

W5@Odyssey, 2 Queen's Quay, Belfast BT3 9QQ,

Northern Ireland, UK

S. E. Perkins

Cardiff School of Biosciences, Biomedical Sciences

Building, Museum Avenue, Cardiff CF10 3AX, UK

C. Lawton

Martin Ryan Institute, NUI, Galway, Ireland

J. M. Meehan · T. J. Hayden

School of Biology \& Environmental Science, University

College Dublin, Belfield, Dublin 4, Ireland 
following introduction. We demonstrate that a twoparameter empirical model and a rule-based spatially explicit simulation are sufficient to accurately describe the invasion history of a species that exhibits a complex, density-dependent pattern of dispersal.

Keywords Invasive species - Reaction-diffusion · Non-commensal · Mammal · Island · Landscape . Dispersal $\cdot$ Life-history

\section{Introduction}

Species' introductions can be highly detrimental to natural communities, ecosystem integrity, agriculture, fisheries and public health (Lee 2002). However, they provide an opportunity to examine the processes which lead to changes in a species' range, of relevance to both pure and applied population biology (Lodge et al. 2006; Parmesan and Yohe 2003).

Successful colonisation by a non-native species progresses through three stages: (i) inoculation, (ii) establishment (often including a lag period) and (iii) range expansion (Williamson 1996). There are three distinct patterns of range expansion (Shigesada and Kawasaki 1997; Shigesada et al. 1995): Type 1 is characterised by a radial invasion range (i.e. the square-root of the area of the range) which increases linearly as a function of time. Such a pattern is derived from population growth and simple short-distance diffusion or local Brownian motion (Skellam 1951). Expansion takes place only along the edge of the range because in this situation dispersing individuals settle in the vicinity of the parent population. Type 2 is characterised by a biphasic expansion typically with a slow rate of spread initially followed by a higher constant rate and Type 3 is characterised by an exponential rate of spread i.e. accelerating increase over time (Shigesada and Kawasaki 1997; Shigesada et al. 1995). Patterns 2 and 3 occur in species capable of long-distance dispersal relative to range size where new colonies are established far beyond the edge of the range. These scenarios assume uniform dispersal based on demographic processes but species can often possess complex reactions to landscape and habitat structure which influence their direction and rate of spread (Gustafson and Gardner 1996).

Dispersal rates and range expansion may vary according to the distribution and quality of suitable habitat (Morgia et al. 2011; Ovaskainen 2004). Indeed, the distribution and abundance of suitable habitat predicate successful colonization (Hanski 1999). Physical features such as water bodies and mountain ranges may act as barriers to dispersal (Gerlach and Musolf 2000; Kozakiewicz et al. 2009). Variation in climate, resources and landscape connectivity generate differential rates of expansion across space (Grosholz 1996; Phillips et al. 2008; Urban et al. 2008; With 2002). Using model systems to understand how landscape influences the spread of colonizing species is critical to making realistic predictions of the likelihood of introduction and establishment of non-native species or successful re-introductions for conservation purposes (Morgia et al. 2011; Ovaskainen 2004).

Small to medium-sized mammals include some of the most notorious invasive species (Clout and Veitch 2002), including the house mouse (Mus musculus), Rattus species ( $R$. rattus, $R$. norvegicus, $R$. exulans), the European rabbit (Oryctolagus cuniculus), coypu (Mycocastor coypus), muskrat (Ondatra zibethicus), grey squirrel (Sciurus carolinensis) and American mink (Neovison vison). However, it is rather rare to have the opportunity to study a small mammal invasion where the range is continuing to expand, and where the process of invasion is not being modified by an eradication program. Here we examine the range expansion of a non-commensal small mammal where the data available allow a particularly detailed analysis of the invasion process. The bank vole (Myodes glareolus, formerly of the genus Clethrionomys) is widely distributed throughout Eurasia from Iberia to central Siberia and from northern Scandinavia to the Mediterranean but was not recorded in Ireland until 1964 (Claassens and O'Gorman 1965). Analysis of mitochondrial DNA and vole parasite populations supports a single colonisation event in the late $1920 \mathrm{~s}$ involving a small number of founders arriving on the southern shore of the Shannon estuary (Fairley 1971a, 1997; Ryan et al. 1996; Stuart et al. 2007). The latter suggest that to date of introduction was 1926 at Foynes, Co Limerick, where heavy, earth moving equipment was landed from Germany prior to the construction of the Shannon hydroelectricity scheme. The first systematic distribution surveys established that the bank vole was restricted to south-west Ireland (Fairley 1971b; Fairley and O'Donnell 1970) and hindcast extrapolations suggested that the species began to expand its range (possibly after an initial lag period) sometime 
during the 1940s or 1950s, expanding in all directions at an estimated rate of $1.0-4.5 \mathrm{~km}$ year $^{-1}$ (Smal and Fairley 1984). Recent work suggests that the bank vole may have major impacts on well-established small mammal communities in Ireland (Montgomery et al. 2012) reducing population density of the wood mouse (Apodemus sylvaticus) and pygmy shrew (Sorex minutus). Further, it interacts with another recent invader, the greater-white toothed shrew Crocidura russula (Tosh et al. 2008), to bring about the extinction (or severe reduction) of the pygmy shrew (Sorex minutus), a rare example of invasional meltdown (Simberloff and Von Holle 1999). Moreover, such changes in the small mammal community are likely to alter ecosystem processes at various trophic levels from plants to predators (Montgomery et al. 2012). Given the impracticality of eradication, it is probable that the bank vole's range in Ireland will continue to expand until the whole island is occupied.

We use an extensive dataset with detailed information on population distribution to determine the mechanisms influencing the invasion and range spread of the bank vole in Ireland. Firstly, we examined how observed expansion rates fitted the expected patterns of Type 1,2, and 3 invasions. Specifically, we constructed a Skellam's reaction-diffusion model from known life history and demographic parameters and examined how these estimates reflected observed expansion rates. Secondly, we developed a rule-based spatially explicit simulation of bank vole dispersal processes accounting for habitat suitability, barriers to dispersal and density dependent processes. Consequently, we describe species range expansion rates and the processes involved theoretically before testing our predictions using empirical data to accurately describe the invasion history. Similarities in small mammal life histories and habitat use may suggest that our results are readily generalizable to other invasive small mammal species elsewhere.

\section{Methods}

\section{Species records}

Bank vole distribution data were collated from previous surveys conducted from 1964 to 2010 providing four key periods: (i) 1969/70 (Fairley 1971b; Fairley and O'Donnell 1970), (ii) 1982 (Smal and Fairley 1984), (iii) 1997-2001 (J. Meehan, unpublished PhD thesis), and, (iv) 2010 (T. White field data, and Montgomery et al. 2012). Incidental records were also collated (Fairley 1985, 1992; Leirs et al. 1987; McHugh and Boyle 2010; McHugh and Lawton 2005; Smal and Fairley 1978; Smiddy and Sleeman 1994). These collated records are shown in Fig. 1.

\section{Observed patterns of range expansion}

Range maps of species' spread were created for 1969/ 70 (including non-systematic data collected from 1964 to 1969$), 1975,1982,1984,1985,1992,2001,2003$ and 2010. Range boundaries for each time-point were fitted using $\alpha$-hull polygons using the R (CRAN 2011) package alphahull where $\alpha=1$ (Burgman and Fox 2003). The land area occupied at each time point was calculated using the $\mathrm{R}$ package geosphere, and the radial invasion range was calculated as $\sqrt{\mathrm{A} / \pi}$, where $\mathrm{A}$ is the invaded area. This assumed a circular distribution for the range area that expands equally in all directions. Used in an uninformed way this may be inappropriate for invasions which proceed in an asymmetric manner, such as that of the bank vole in Ireland whose invasion has been bounded in the southwest by the coast. Therefore, we examined rates of species' spread in different areas of the range by dividing the range into twelve $30^{\circ}$ sectors, meeting at the point of introduction on the southern shore of the Shannon estuary (Fig. 2). Four sectors were dominated by sea and were discarded. The radial invasion range for each sector was calculated as $\sqrt{(\mathrm{A} * 12) / \pi}$. For Ireland as a whole, and for the eight retained sectors, rates of spread were measured by fitting radial invasion range against time using: (a) a linear regression (i.e. constant rate of increase), and, (b) a quadratic regression (i.e. accelerating or decelerating rate of increase).

\section{Reaction-diffusion model}

A traditional reaction-diffusion model (Skellam 1951) was constructed using empirically derived data from life tables for two representative cohorts (Spring- and Autumn-born animals), incorporating bank vole life history and demographic parameters extracted from published literature. Mean bank vole litter size ranges from 3.5 to 4.1 in Britain (Alibhai and Gipps 1985), increasing after the first litter (Gustafsson et al. 1983; 
Fig. 1 Bank vole distribution in Ireland during the 1969/1970, 1982, 2001 and 2010 surveys. Grey filled circles show locations where the bank voles had been found prior to that year, black filled circles show locations where bank voles were caught during that year's survey, while open circles show locations wh ere trapping was conducted but no bank voles were caught

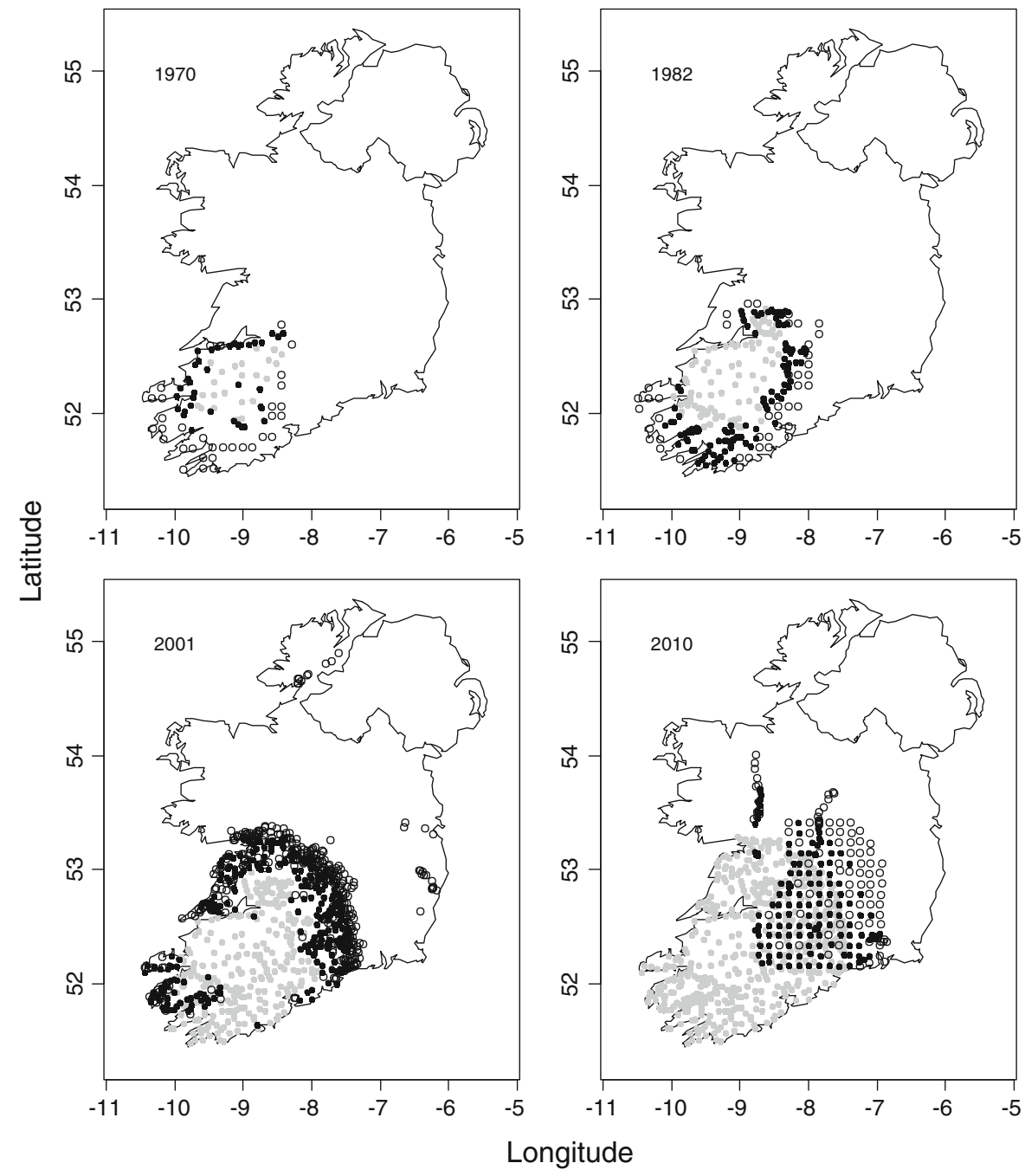

Stenseth and Gustafsson 1985). The sex ratio adheres roughly to 1:1 (Bujalska 1983). For our model, therefore, we assumed that there are 1.5 females in the first litter and 2 females in subsequent litters. Bank vole females are capable of producing litters every 3 weeks (Harris and Yalden 2008) and sexual maturation is normally reached in females only after securing a territory, which we assumed should occur quickly in the low densities typical of an expansion front. Thus, for the spring (mid-April) cohort we assumed that the first litter is born after 6 weeks, with further litters following every 3 weeks thereafter (Shore and Hare 2008). Females are assumed to produce five litters per season (Buchalczyk 1970; Hansson 1990), although, due to mortality, few females achieve maximum productivity. For the autumn (mid-September) cohort, we assumed that the first litters are born in the following spring (midMarch). Survival data for the spring cohort, are from Gliwicz (1983), and for the autumn cohort from S. Rooney (unpublished data) where $50 \%$ of the voles were assumed to survive overwinter.

We calculated the basic reproductive rate as $R_{0}=$ $\Sigma l_{x} b_{x} x$ and the generation time as $T_{c}=\Sigma l_{x} b_{x} x / \Sigma l_{x} b_{x}$ allowing estimation of the intrinsic rate of increase as $r \approx \ln R_{0} / T_{c}$ (Begon et al. 1996) where $l_{x}$ and $b_{x}$ are the proportion of a cohort surviving at start of time period, and number of female offspring produced per female in time interval, respectively. The diffusion coefficient $(D)$ was derived as $D=2 M(t)^{2} / \pi t$, where $M(t)$ is the mean displacement of organisms recaptured at time $t$ (Andow et al. 1990). To determine 
Fig. 2 a Theoretical model of simulated bank vole dispersal using 'condition 9' (see Table 1). Dashed contours show dates used to test model fit. Dotted lines shown predicted ranges in 2025, 2050, 2075 and 2100. b Sectors (1-8) within which radial invasion ranges were calculated. Dashed lines show $\alpha$-hulls for the years 1970, 1982, 2001 and 2010
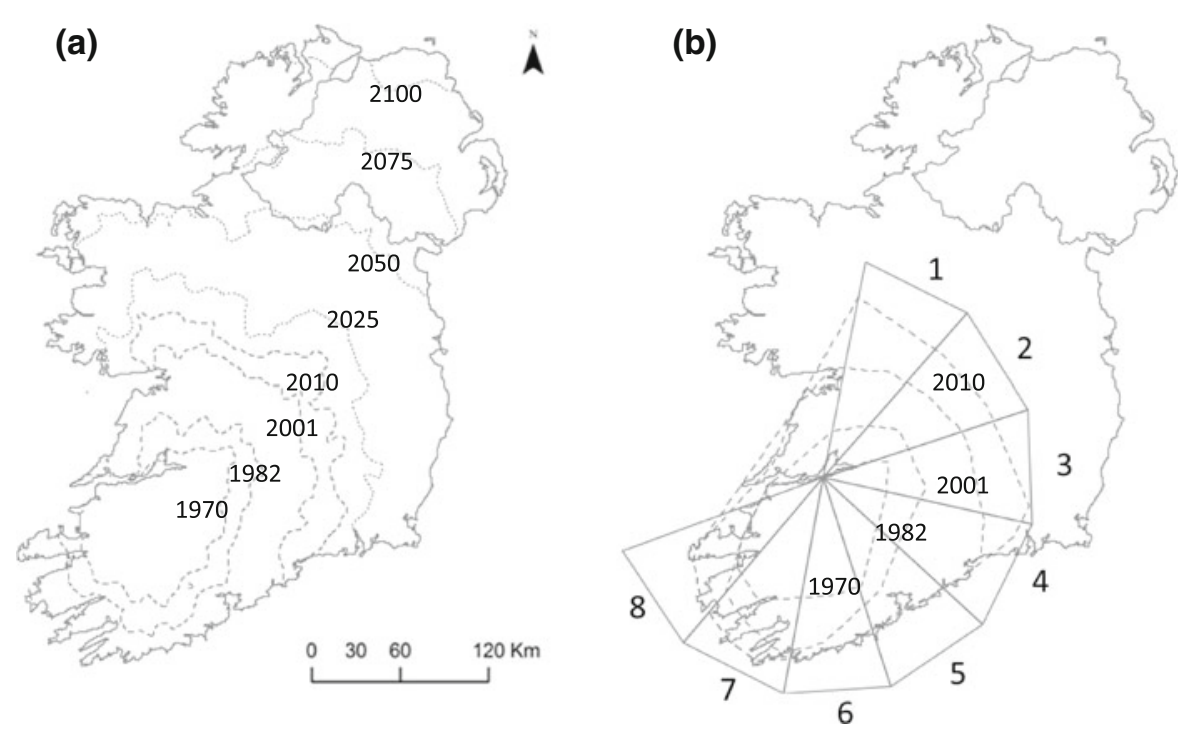

$M(t)$ we used dispersal data from Kozakiewicz et al. (2007). In that capture-mark-recapture study, voles were trapped from May to November at 14-day intervals on a grid allowing detection of movements up to $930 \mathrm{~m}$. As dispersal is at its peak in spring/early summer and autumn (Gliwicz 1992), we assumed a 6 month period for dispersal (April to June and midAugust to mid-November), so the final value of $D$ was adjusted accordingly.

Rule-based spatially explicit simulation

Habitat suitability $(H s)$ of each $1 \mathrm{~km}$ grid square was determined for the bank vole throughout Ireland with a Maximum Entropy Method (MEM) model (Phillips and Dudík 2008), using the software package 'MaxEnt'. The training set (using $80 \%$ of all species records) was restricted to the area occupied by the species during 2010 delineated using a minimum convex polygon of all known records. Explanatory variables included altitude (derived from a Digital Elevation Model) and CORINE land cover (EEA 2000) using the classifications: agriculture with areas of natural vegetation; arable; bog, moor, marsh and heath; broadleaf woodland; coastal habitats; complex agricultural areas; coniferous forest; fresh water; mixed woodland; natural grassland; pasture; scrub; sparse vegetation and urban areas. Climate variables were included for the region: precipitation; seasonality and average minimum monthly temperature (minimum temperature: http://www.worldclim.org). Relationships were assumed to be a combination of linear and quadratic response forms only. A test set (using $20 \%$ of records) was used to evaluate the predictive utility of the model using the Area Under the Curve (AUC) statistic. The final model was projected throughout Ireland.

Colonisation processes were simulated using a grid at a spatial resolution of $1 \mathrm{~km}$ and assuming a total of nine colonisation conditions (Table 1). Each condition assumed a different combination of possible parameters including: (i) dispersal direction, (ii) differing threshold densities at which dispersal occurred, and, (iii) the number of emigrating individuals that dispersed. These parameters may be independent or a function of $H s$. The single point of introduction from which population spread was simulated, was assumed to be the same as in reaction diffusion models (above).

The density $(d)$ at which the population within any $1 \mathrm{~km}$ square starts to contribute dispersing individuals to adjacent squares was defined as: (a) 'fixed' $(d=1)$ irrespective of $H s$, or, (b) or as an increasing function of $H s\left(d=1 * H_{s}\right)$. The number of dispersing individuals was defined as: (a) 'fixed' i.e. all recruits resulting from exponential population growth $(\mathrm{Nr})$, or, (b) as a function of $H s\left(N r * H_{s}\right)$. Dispersal direction $(D d)$ was assumed to be: (a) random, (b) toward an adjacent square with the lowest population density, (c) towards areas with the highest landscape suitability, or (d) least-cost path i.e. the direction of average highest $H s$. Simulated spread of the population was restricted to terrestrial habitats only with estuaries and lakes classified as having zero 
Table 1 Descriptions of theoretical models each assuming one of 9 'Conditions' to simulate bank vole invasion processes; $\left(H^{s}\right)$ Habitat suitability derived from Maximum Entropy

\begin{tabular}{llll}
\hline Condition & Dispersal direction & $\begin{array}{l}\text { Threshold density for } \\
\text { emigration }\end{array}$ & $\begin{array}{l}\text { No. of dispersing } \\
\text { individuals }\end{array}$ \\
\hline 1 & Random & Fixed (1) & Fixed $(\mathrm{Nr} * 1)$ \\
2 & Random & Fixed & Variable $\left(\mathrm{Nr} * H^{s}\right)$ \\
3 & Random & Variable $\left(1^{s} H^{s}\right)$ & Variable \\
4 & Non-random (toward lowest population density) & Fixed & Variable \\
5 & Non-random (toward lowest population density) & Variable & Variable \\
6 & Non-random (towards most suitable landscape) & Fixed & Variable \\
7 & Non-random (towards most suitable landscape) & Variable & Variable \\
8 & Non-random (least-cost path towards most suitable landscape) & Fixed & Variable \\
9 & Non-random (least-cost path towards most suitable landscape) & Variable & Variable \\
\hline
\end{tabular}

Method modelling; $(\mathrm{Nr}$ ) Number of new individuals per generation in a exponentially increasing population landscape suitability. Simulations were conducted with a range of interaction distances $\left(I d^{\mathrm{km}}=2,3,5,7\right.$ or $11 \mathrm{~km})$. The interaction distances were those distances over which individuals are apparently aware of the surrounding habitat and represent their maximum dispersal distance. For simulations using the least-cost path the average $H s$ was calculated for adjacent grid squares up to the defined the $I d^{\mathrm{km}}$. They do not represent the rate of range expansion of the population as a whole. Candidate $I d^{\mathrm{km}}$ were not factors of each other and hence allowed independent patterns of dispersal to be generated. The simulation was run for a total of 200 iterations, where each iteration of the model corresponded to 1 year. Simulations were run using custom written script in R (CRAN 2011).

Contour maps of the simulated populations at each 10-iteration interval were created for each of the nine colonisation conditions after 100 replicates for each condition using ArcGIS 10 (ESRI, California, USA). These models were tested using the bank vole range during 1970, 1982, 2001 and 2010 and their fit was evaluated using the AUC statistic. The colonisation condition and $I d^{\mathrm{km}}$ with the highest AUC value was selected as the best simulation model describing the invasion process of the bank vole.

\section{Results}

Observed patterns of range expansion

When considering the bank vole range across Ireland, the radial invasion range increased linearly with time $\left(\beta=1.315 \pm 0.059, p<0.0001\right.$, adj. $\left.r^{2}=0.98\right)$, and suggested that the expansion of the range started around 1938 (Fig. 3). Assuming that the introduction occurred in 1926 (Stuart et al. 2007), this implies an initial lag period of approximately 12 years. When the range was divided into eight $30^{\circ}$ sectors (Fig. 2), we found variation in the rate of range expansion (Table 2; Fig. 4). The radial invasion range increased linearly with time in sectors $1-4$ with a constant rate of spread between 2.23 and $2.63 \mathrm{~km}_{\text {year }}{ }^{-1}$. The radial invasion range for sectors 5-8 reached an asymptote and a quadratic regression was the best fit for sectors 6 and 7 , since the rate of expansion was constrained by

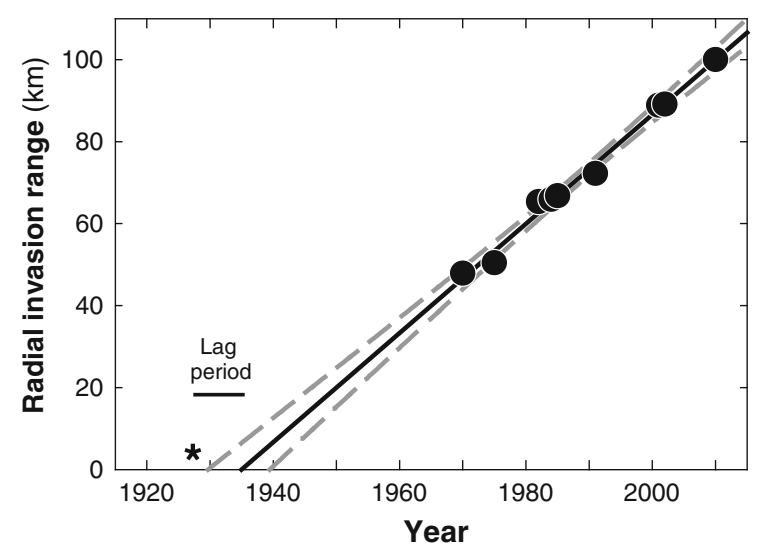

Fig. 3 Radial invasion range for bank voles in Ireland against time $\left(\beta=1.315 \pm 0.059, p<0.0001, r^{2}=0.98\right)$. Dashed lines show $95 \%$ confidence intervals, star represents the suggested date of introduction in 1926 and a potential lag period of 12 years is shown as a line 
Table 2 Regression coefficients for the rates of range expansion for four sectors of the bank vole range and ANOVA results for differences between linear and quadratic functions

\begin{tabular}{|c|c|c|c|c|c|c|}
\hline \multirow[t]{2}{*}{ Sector } & \multicolumn{3}{|c|}{ Basic linear model $(r i r \sim y r)$} & \multicolumn{2}{|c|}{ ANOVA } & \multirow{2}{*}{$\begin{array}{l}\text { Predicted expansion } \\
\text { start date }\end{array}$} \\
\hline & $\beta \pm \mathrm{SE}$ & $p$ & $r^{2}$ & $F$ & $p$ & \\
\hline 1 & $2.633 \pm 0.156$ & $<0.0001$ & 0.976 & 1.778 & 0.240 & 1970 \\
\hline 2 & $2.337 \pm 0.201$ & $<0.0001$ & 0.951 & 0.258 & 0.633 & 1961 \\
\hline 3 & $2.230 \pm 0.141$ & $<0.0001$ & 0.973 & 4.307 & 0.093 & 1953 \\
\hline 4 & $2.252 \pm 0.127$ & $<0.0001$ & 0.978 & 0.016 & 0.905 & 1952 \\
\hline 5 & $1.301 \pm 0.127$ & $<0.0001$ & 0.937 & 4.688 & 0.083 & 1922 \\
\hline 6 & $0.923 \pm 0.215$ & $<0.01$ & 0.713 & 11.818 & $0.018 *$ & 1948 \\
\hline 7 & $0.749 \pm 0.170$ & $<0.01$ & 0.725 & 11.848 & $0.018 *$ & 1941 \\
\hline 8 & $0.719 \pm 0.104$ & $<0.001$ & 0.871 & 1.534 & 0.271 & NA \\
\hline
\end{tabular}

the coast. Start dates of expansion were predicted for these sectors using the best model (linear or quadratic) are shown in Table 2. Sector 8 was omitted as most of the available area of this sector was occupied prior to 1970 and rates calculated from 1970 to 2010 would have been artificially low, giving unreasonably early start dates. For sectors 1 and 2, the predicted dates of expansion were 1970 and 1961, respectively. These two sectors crossed the River Shannon, which may have delayed the bank vole expansion. For the remaining sectors, the predicted date of expansion varied from 1922 to 1953 .

\section{Reaction-diffusion model}

Following Skellam (1951), the intrinsic rate of population increase, $r$ (change in population size per individual per unit time) was calculated as 2.56 year $^{-1}$ for the Spring cohort where $R_{0}=2.55$ individuals individual $^{-1}$ generation $^{-1}$ and $T_{c}=19$ weeks
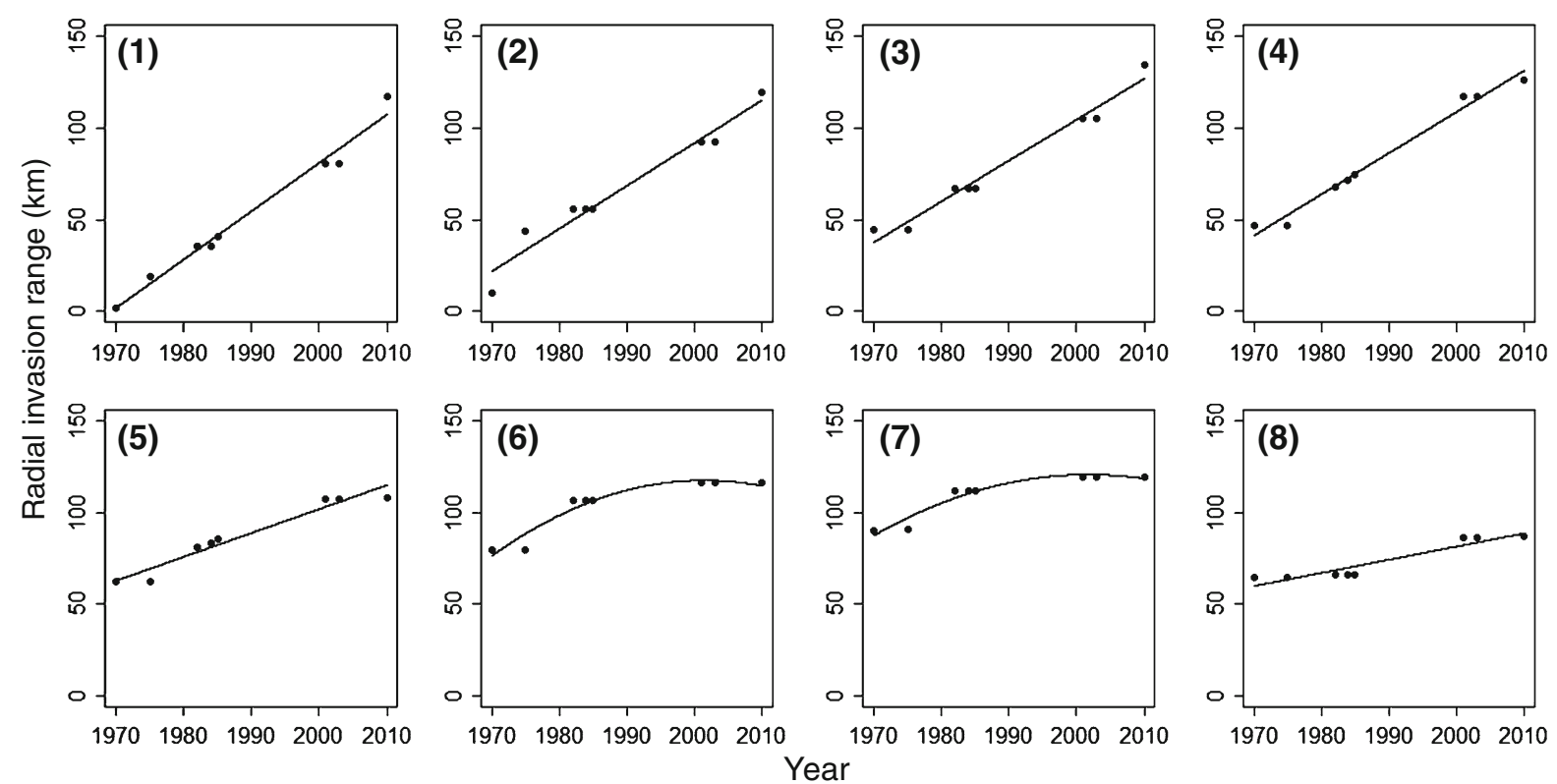

Fig. 4 Radial invasion ranges for bank voles over time in the eight sectors shown in Fig. 2 
Table 3 Life table for a mid-April bank vole cohort where $x=$ time period, $n_{x}=$ number of animals alive at $x, l_{x}=$ proportion of cohort surviving at start of time period,

\begin{tabular}{|c|c|c|c|c|c|c|c|}
\hline Date & $x$ (3 weeks) & $n_{x}$ & $l_{x}$ & $q_{x}$ & $b_{x}$ & $l_{x} b_{x}$ & $l_{x} b_{x} x$ \\
\hline April & 1 & 100.0 & 1.000 & 0.35 & 0.00 & 0.000 & 0.000 \\
\hline May & 2 & 65.0 & 0.650 & 0.30 & 0.00 & 0.000 & 0.000 \\
\hline June & 3 & 35.0 & 0.350 & 0.06 & 1.50 & 0.525 & 1.575 \\
\hline June & 4 & 29.0 & 0.290 & 0.06 & 2.00 & 0.580 & 2.320 \\
\hline July & 5 & 23.0 & 0.230 & 0.04 & 2.00 & 0.460 & 2.300 \\
\hline August & 6 & 19.0 & 0.190 & 0.04 & 2.00 & 0.380 & 2.280 \\
\hline September & 7 & 15.0 & 0.150 & 0.03 & 2.00 & 0.300 & 2.100 \\
\hline September & 8 & 12.5 & 0.125 & 0.03 & 0.00 & 0.000 & 0.000 \\
\hline October & 9 & 10.0 & 0.100 & 0.02 & 0.00 & 0.000 & 0.000 \\
\hline November & 10 & 8.5 & 0.085 & 0.02 & 0.00 & 0.000 & 0.000 \\
\hline December & 11 & 7.0 & 0.070 & 0.01 & 0.00 & 0.000 & 0.000 \\
\hline December & 12 & 6.5 & 0.065 & 0.01 & 0.00 & 0.000 & 0.000 \\
\hline January & 13 & 6.0 & 0.060 & 0.01 & 0.00 & 0.000 & 0.000 \\
\hline February & 14 & 5.5 & 0.055 & 0.01 & 0.00 & 0.000 & 0.000 \\
\hline March & 15 & 5.0 & 0.050 & 0.01 & 0.00 & 0.000 & 0.000 \\
\hline March & 16 & 4.5 & 0.045 & 0.01 & 0.00 & 0.000 & 0.000 \\
\hline April & 17 & 4.0 & 0.040 & 0.01 & 2.00 & 0.080 & 1.360 \\
\hline May & 18 & 3.5 & 0.035 & 0.01 & 2.00 & 0.070 & 1.260 \\
\hline June & 19 & 3.0 & 0.030 & 0.01 & 2.00 & 0.060 & 1.140 \\
\hline June & 20 & 2.5 & 0.025 & 0.01 & 2.00 & 0.050 & 1.000 \\
\hline July & 21 & 2.0 & 0.020 & 0.00 & 2.00 & 0.040 & 0.840 \\
\hline August & 22 & 1.8 & 0.018 & 0.00 & 0.00 & 0.000 & 0.000 \\
\hline September & 23 & 1.5 & 0.015 & 0.00 & 0.00 & 0.000 & 0.000 \\
\hline September & 24 & 1.3 & 0.013 & 0.00 & 0.00 & 0.000 & 0.000 \\
\hline October & 25 & 1.0 & 0.010 & 0.01 & 0.00 & 0.000 & 0.000 \\
\hline November & 26 & 0.5 & 0.005 & 0.01 & 0.00 & 0.000 & 0.000 \\
\hline December & 27 & 0.0 & 0.000 & 0.00 & 0.00 & 0.000 & 0.000 \\
\hline
\end{tabular}

$\sum l_{x} b_{x}\left(R_{0}\right)=2.545$

$\sum l_{x} b_{x} x=16.175$

Generation time $\left(T_{c}\right)=\sum l_{x} b_{x} x / \sum l_{x} b_{x}=2.545 / 16.175=6.3563$-week periods $=19$ weeks

$r=\ln \left(R_{0}\right) / T_{c}=\ln 2.545 / 19$ weeks $=0.0492$ week $^{-1}=2.56$ year $^{-1}$

and 2.31 year $^{-1}$ for the Autumn cohort where $R_{0}=3.71$ and $T_{c}=29.5$ weeks (Tables 3,4). As these $r$ values were very similar, subsequent calculations assumed an intrinsic rate of increase of $r=2.50$ year $^{-1}$. The mean dispersal distance of all capture-mark-recapture trapped female bank voles, $M(t)=81 \mathrm{~m}$ over a period of 1-3 days, provided a range of diffusion coefficients, $D=0.26-0.77 \mathrm{~km}^{2}$ per year (accounting for peak dispersal adjustment). With these values for $r$ and $D$, the empirically-derived $q_{x}=$ mortality rate during time period, $b_{x}=$ number of female offspring born per female during time period 
Table 4 Life table for a September bank vole cohort where $x=$ time period, $n_{x}=$ number of animals alive at $x, l_{x}=$ proportion of cohort surviving at start of time period,

\begin{tabular}{|c|c|c|c|c|c|c|c|}
\hline Date & $x$ (3 weeks) & $n_{x}$ & $l_{x}$ & $q_{x}$ & $b_{x}$ & $l_{x} b_{x}$ & $l_{x} b_{x} x$ \\
\hline September & 1 & 100.0 & 1.000 & 0.500 & 0.00 & 0.000 & 0.000 \\
\hline March & 8 & 50.0 & 0.500 & 0.050 & 1.50 & 0.750 & 6.000 \\
\hline March & 9 & 45.0 & 0.450 & 0.050 & 2.00 & 0.900 & 8.100 \\
\hline April & 10 & 40.0 & 0.400 & 0.050 & 2.00 & 0.800 & 8.000 \\
\hline May & 11 & 35.0 & 0.350 & 0.070 & 2.00 & 0.700 & 7.700 \\
\hline May & 12 & 28.0 & 0.280 & 0.070 & 2.00 & 0.560 & 6.720 \\
\hline June & 13 & 21.0 & 0.210 & 0.060 & 0.00 & 0.000 & 0.000 \\
\hline July & 14 & 15.0 & 0.150 & 0.040 & 0.00 & 0.000 & 0.000 \\
\hline August & 15 & 11.0 & 0.110 & 0.030 & 0.00 & 0.000 & 0.000 \\
\hline August & 16 & 8.0 & 0.080 & 0.030 & 0.00 & 0.000 & 0.000 \\
\hline September & 17 & 5.0 & 0.050 & 0.025 & 0.00 & 0.000 & 0.000 \\
\hline October & 18 & 2.5 & 0.025 & 0.025 & 0.00 & 0.000 & 0.000 \\
\hline November & 20 & 0.0 & 0.000 & 0.000 & 0.00 & 0.000 & 0.000 \\
\hline
\end{tabular}

$\sum l_{x} b_{x}\left(R_{0}\right)=3.71$

$\sum l_{x} b_{x} x=36.52$

Generation time $\left(T_{c}\right)=\sum l_{x} b_{x} x / \sum l_{x} b_{x}=3.71 / 36.52=9.8443$-week periods $=29.5$ weeks

$r=\ln \left(R_{0}\right) / T_{c}=\ln 3.71 / 29.5$ weeks $=0.0444$ week $^{-1}=2.31$ year $^{-1}$

farmland was negative associated with bank vole presence. Temperature, broad leaf woodland, mixed woodland and pasture was positively associated with bank vole presence, although there were limits above which further increase in these variables had no effect on habitat suitability for bank voles.

Of the nine candidate 'conditions' tested, condition 9 had the best fit, having the highest AUC value (Table 5), i.e. the density at which the population reached a threshold and started to donate emigrating individuals $\left(d=1 * H_{s}\right)$ and the number of individuals that dispersed $\left(\mathrm{Nr} * \mathrm{H}_{s}\right)$ were an increasing function of habitat suitability whilst the dispersal direction was along a path of average highest habitat suitability. An $I d^{\mathrm{km}}$ of $7 \mathrm{~km}$ per iteration achieved the best fit for the observed range during 1970 (AUC $=82.0 \%$ ), although there was also strong support for an $I d^{\mathrm{km}}$ of $5 \mathrm{~km}(\mathrm{AUC}=81.9 \%)$. The best fit for the observed range during 1982, 2001 and 2010 was an $I d^{\mathrm{km}}$ of $5 \mathrm{~km}$ (Table 5). The number of simulated iterations (years) required to reach maximum extent of the species' range during 1970, 1982, 2001 and 2010, were 40, 50, 70 and 80 respectively (Fig. 2). Simulations allowed the future range in 2025, 2050, 2075 and 2100 to be predicted (Fig. 2). Bank voles were predicted to have colonised the entire island of Ireland by the year 2100 . $q_{x}=$ mortality rate during time period, $b_{x}=$ number of female offspring born per female during time period 

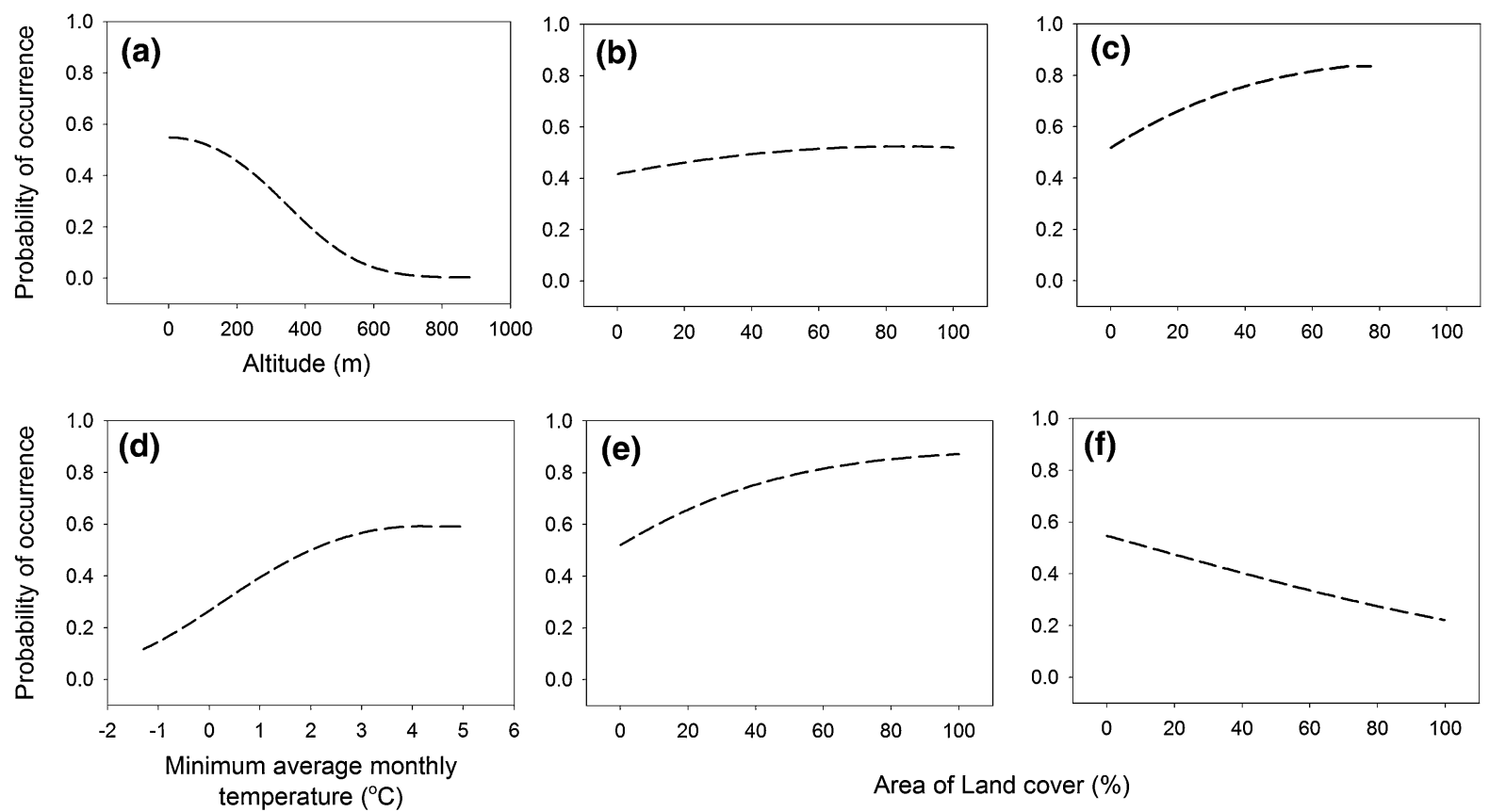

Fig. 5 The relationship of the variables which contributed significantly to the Maximum Entropy Method (MEM) habitat suitability model. a Altitude; b Pasture; c Broadleaf woodland; d Minimum average monthly temperature; e Mixed woodland and $\mathbf{f}$ Arable farmland

of $5 \mathrm{~km}$, although there was some support for a larger interaction distance prior to 1970 . Models fitted better when dispersing individuals moved along a least-cost path i.e. the landscape path of least resistance. Consequently, barriers such as water bodies and areas of lower suitability impede or stop dispersal in certain directions providing an explanation for the declining rates of radial invasion range in directions where animals encountered mountainous terrain or the coast, notably the Shannon estuary in the immediate area north of the focal point of introduction. The southern third of Ireland is bisected by uplands and peninsulas and has scattered areas of extensive bog, all of which may be less suitable for voles than the lowland pastoral land with banks and hedges favoured by this species (Montgomery et al. 2012).

Whilst local habitat variability influences the rate of spread, on a larger scale the invasion resembles a simple reaction-diffusion process. The reaction-diffusion model has given similarly good predictions of the rate of range expansions in other small/mediumsized mammalian invaders, for example, the muskrat in Europe (Andow et al. 1990; Skellam 1951) and the coypu in Britain (Reeves and Usher 1989). It is 
thought to be appropriate for species with localised dispersal. In the case of the bank vole, females are territorial and usually settle close to their natal range (Koskela et al. 1997; Ylönen 1988), while males utilize home ranges that overlap those of several females (Ylönen and Mappes 1995). For small mammals, dispersal is costly, due both to risk of predation during dispersal (Smith and Batzli 2006) and the difficulty in establishing themselves in a new population (Hahne et al. 2011). There are data for small mammals that suggest that emigration from natal populations solely reflects positive density-dependent dispersal and agonistic behaviour from conspecifics (Hahne et al. 2011; Matthysen 2005). Given the costs associated with dispersal, small mammals should disperse only as far as the nearest suitable unoccupied space (Waser 1985). For species with a fat-tailed dispersal kernel, where many individuals disperse long distances, such as insects and wind-dispersed plants, the reaction-diffusion model is known to underestimate the rate of range expansion (Kot et al. 1996). For small mammals, relatively short-distance dispersal, albeit influenced by local habitat quality, may generate dispersal kernels which are sufficiently close approximations to the normal distribution that the reaction-diffusion model may be valid.

Considering the entire range, the rate of range expansion for the bank vole appeared to be linear and did not accelerate once the species is established. This overall description masks local heterogeneity in the rate of range expansion (Fig. 4). Estimated rates of expansion varied between 2.23 and $2.63 \mathrm{~km} \mathrm{year}^{-1}$ in areas where the range was unconstrained (i.e. noncoastal) and appeared to be linear with time. These rates are at the upper estimate of expansion rates derived by species life history parameters, suggesting that the current colonisation of Ireland is occurring at a rate at the upper limits of the species capability. Our life history data were obtained from British and European studies. However, bank voles in Ireland have fewer competitors and parasites (S. Perkins unpublished data) than conspecifics in Britain and continental Europe. The invasive population may be able to realise higher reproductive rates than elsewhere, perhaps accounting for the rapid rate of range expansion.

Using the radial invasion range for the whole of Ireland, extrapolation suggested that the range began expanding in 1938. As this conceals hidden variation, we also estimated start dates for each of the sectors. For sectors 1 and 2 these dates were recent: 1970 and 1961 respectively. Here, the range expansion may have been held up for several years until bank voles managed to cross the River Shannon; a natural barrier to dispersal. In other sectors the predicted start of expansion varied from 1922 to 1953. If the bank vole was introduced in 1926 (Stuart et al. 2007), this suggests an initial lag in the bank vole range expansion, at least in some areas. It is unfortunate that there are so few data on the bank vole distribution before 1970, as we can say little for certain about the early phase of the expansion. We consider that the bank vole invasion represents either a Type 1 expansion, potentially with an initial lag, or a Type 2 (biphasic) expansion with a lower rate of expansion prior to 1970 . For the sectors (1 and 2) where expansion began around 1970 we have more complete data. Here the expansion has remained linear, giving more support to a Type 1 invasion with a lag. Such a lag may be a general phenomenon, due again to the high costs of dispersal for small mammals. If small mammals only disperse when forced to do so by population pressures, time will be required to fill local habitat patches before the population reaches a sufficient density to encourage dispersal, and hence range expansion.

Eradication of a highly numerous small mammal, such as the bank vole, is highly unfeasible. The only means of limiting the effect of the bank vole in Ireland is not eradication or population intervention (i.e. management) but landscape and habitat scale changes which disadvantage the invasive species whilst advantaging the indigenous species by providing 'habitat' refuges (see Montgomery et al. 2012 for specific recommendations). With no management plan presently in place, there is a unique opportunity for ongoing monitoring of invasion processes, and to determine whether or not the rate of expansion remains linear, as predicted if the invasion follows a Type 1 pattern. The expanding wave-front in 2010/11 was located approximately $240 \mathrm{~km}$ south of the most northerly extent of the island. If we assume expansion continues at a rate of roughly $2.5 \mathrm{~km}$ per year, the bank vole will occupy the whole island by around 2100 . Forward projections from the simulation model gave very similar results (Fig. 2).

The linear rate of expansion for the bank vole stands in marked contrast to that of another wellstudied invader, the cane toad (Bufo marinus) in 
Australia, whose rate of invasion is accelerating over time due to the evolution of increased dispersal ability (Phillips et al. 2006). The extensive data set available for the bank vole in Ireland will allow this invasion to become a model comparable to the cane toad in Australia, amongst other things helping to elucidate the factors determining the evolution of life-history parameters during range expansions.

Recent years have seen a proliferation of increasingly complex models of range expansion, incorporating variation in habitat, dispersal kernels and adaptive evolution (Hastings et al. 2005; Phillips et al. 2008). However, for many species, available information may not allow for parameterisation of more complex invasion models. For effective management of invasive species, it would be useful to predict potential rates of invasion for a wide range of species (Lodge et al. 2006), and this may require the use of simple models (Wilson et al. 2009). We demonstrate here a simple rule-based spatially-explicit simulation model that we suggest can be applied to a wide range of invasive species, adding to our understanding of the way that species may colonise and the interaction of dispersal and landscape, and also developing testable hypothesis of dispersal. We also predict that for many species, especially small terrestrial mammal species, the reaction-diffusion model will continue to be informative about range expansion processes on a larger scale.

Acknowledgments Dr. Thomas White was supported by a Marie Curie Outgoing International Fellowship and a Heredity Fieldwork Grant from The Genetics Society. Dr. Mathieu Lundy was supported by The National Parks and Wildlife Service, Department of Arts, Heritage and the Gaeltacht (Republic of Ireland). Dr. Neil Reid was supported by the Natural Heritage Research Partnership (NHRP) between the Northern Ireland Environment Agency (NIEA) and Quercus, Queen's University Belfast (QUB). Dr. Sarah Perkins was supported by a Marie Curie Intra-European Fellowship.

\section{References}

Alibhai SK, Gipps JHW (1985) The population dynamics of bank voles. Symp Zool Soc Lond 55:277-313

Andow DA, Kareiva PM, Levin SA et al (1990) Spread of invading organisms. Landsc Ecol 4:177-188

Begon M, Harper JL, Townsend CR (1996) Ecology. Blackwell, Oxford

Buchalczyk A (1970) Reproduction, mortality and longevity of the bank vole under laboratory conditions. Acta Theriol 15:153-176
Bujalska G (1983) Reproduction. In: Petrusewicz K (ed) Ecology of the Bank Vole. Acta Theriol 28(Suppl. 1):148-161

Burgman MA, Fox JC (2003) Bias in species range estimates from minimum convex polygons: implications for conservation and options for improved planning. Anim Conserv 6:19-28

Claassens AJM, O'Gorman F (1965) The bank vole Clethrionomys glareolus Schreber-a mammal new to Ireland. Nature 205:923-924

Clout MN, Veitch CR (2002) Turning the tide of biological invasion: the potential for eradicating invasive species. IUCN SSC Invasive Species Specialist Group, Gland

CRAN (2011) R Development Core Team (http://cran. r-project.org/)

Fairley JS (1971a) Malareus penicilliger mustelae: a flea new to Ireland. Entomol Mon Mag 107:44

Fairley JS (1971b) The present distribution of the bank vole Clethrionomys glareolus Schreber in Ireland. P Roy Irish Acad B 71:183-189

Fairley JS (1985) Bank vole in County Galway. Irish Nat J 21:544

Fairley JS (1992) Bank voles in County Waterford. Irish Nat J 24:174

Fairley JS (1997) Fleas from bank voles and field mice including Malaraeus penicilliger mustelae (Dale) and abundant Rhadinopsylla pentacantha (Rothschild). Irish Nat J 25:341-342

Fairley JS, O'Donnell T (1970) The distribution of the bank vole Clethrionomys glareolus in south-west Ireland. J Zool 161:273-276

Gerlach G, Musolf K (2000) Fragmentation of landscape as a cause for genetic subdivision in bank voles. Cons Biol 14:1066-1074

Gliwicz J (1983) Survival and life span. In: Petrusewicz K (ed) Ecology of the bank vole. Acta Theriol 28(Suppl. 1):161-172

Gliwicz J (1992) Patterns of dispersal in non-cyclic populations of small rodents. In: Stenseth NC and Lidicker WZJ (eds) Animal dispersal: small mammals as a model. Chapman \& Hall, London, pp 147-159

Grosholz ED (1996) Contrasting rates of spread for introduced species in terrestrial and marine systems. Ecology 77:1680-1686

Gustafson EJ, Gardner RH (1996) The effect of landscape heterogeneity on the probability of patch colonization. Ecology 77:94-107

Gustafsson TO, Andersson CB, Westlin LM (1983) Reproduction in laboratory colonies of bank voles, Clethrionomys glareolus, originating from populations with different degrees of cyclicity. Oikos 40:182-188

Hahne J, Jenkins T, Halle S et al (2011) Establishment success and resulting fitness consequences for vole dispersers. Oikos 120:95-105

Hanski I (1999) Metapopulation ecology. Oxford University Press, Oxford

Hansson L (1990) Breeding of captive bank voles (Clethrionomys glareolus) related to dynamics of source populations. J Reprod Fertil 89:769-772

Harris S, Yalden DW (2008) Mammals of the British Isles: handbook. Mammal Society, Southampton 
Hastings A, Cuddington K, Davies KF et al (2005) The spatial spread of invasions: new developments in theory and evidence. Ecol Lett 8:91-101

Koskela E, Mappes T, Ylonen H (1997) Territorial behaviour and reproductive success of bank vole Clethrionomys glareolus females. J Anim Ecol 66:341-349

Kot M, Lewis MA, van den Driessche P (1996) Dispersal data and the spread of invading organisms. Ecology 77: 2027-2042

Kozakiewicz M, Choluj A, Kozakiewicz A (2007) Long-distance movements of individuals in a free-living bank vole population: an important element of male breeding strategy. Acta Theriol 52:339-348

Kozakiewicz M, Gortat T, Panagiotopoulou H et al (2009) The spatial genetic structure of bank vole (Myodes glareolus) and yellow-necked mouse (Apodemus flavicollis) populations: the effect of distance and habitat barriers. Anim Biol 59:169-187

Lee CE (2002) Evolutionary genetics of invasive species. TREE 17:386-391

Leirs H, Antonissen A, Bohets H et al (1987) Additional data on the distribution of the bank vole, Clethrionomys glareolus (Shreber, 1780), on the Beara Peninsula, Cos Cork and Kerry. Irish Nat J 22:321-322

Lodge DM, Williams S, MacIsaac HJ et al (2006) Biological invasions: recommendations for US policy and management. Ecol Appl 16:2035-2054

Matthysen E (2005) Density-dependent dispersal in birds and mammals. Ecography 28:403-416

McHugh M, Boyle P (2010) Observation of a bank vole (Myodes glareolus Schreber, 1780) in north Co. Galway. Irish Nat J 31:63

McHugh M, Lawton C (2005) Bank vole Clethrionomys glareoulus, Schreber in Galway. Irish Nat J 28:83

Montgomery WI, Lundy ML, Reid N (2012) Invasional meltdown: evidence for unexpected consequences and cumulative impacts of multispecies invasions. Biol Invasions. doi:10.1007/s10530-011-0142-4

Morgia V, Malenotti E, Badino G et al (2011) Where do we go from here? Dispersal simulations shed light on the role of landscape structure in determining animal redistribution after reintroduction. Landsc Ecol 26:969-981

Ovaskainen O (2004) Analytical and numerical tools for diffusion-based movement models. Theor Pop Biol 73:198-211

Parmesan C, Yohe G (2003) A globally coherent fingerprint of climate change impacts across natural systems. Nature 421:37-42

Phillips SJ, Dudík M (2008) Modeling of species distributions with Maxent: new extensions and a comprehensive evaluation. Ecography 31:161-175

Phillips BL, Brown GP, Webb JK et al (2006) Invasion and the evolution of speed in toads. Nature 439:803

Phillips BL, Chipperfield JD, Kearney MR (2008) The toad ahead: challenges of modelling the range and spread of an invasive species. Wildl Res 35:222-234

Reeves SA, Usher MB (1989) Application of a diffusion model to the spread of an invasive species-the coypu in Great Britain. Ecol Model 47:217-232
Ryan A, Duke E, Fairley JS (1996) Mitochondrial DNA in bank voles Clethrionomys glareolus in Ireland: evidence for a small founder population and localized founder effects. Acta Theriol 41:45-50

Shigesada N, Kawasaki K (1997) Biological invasions: theory and practice. Oxford University Press, Oxford

Shigesada N, Kawasaki K, Takeda Y (1995) Modeling stratified diffusion in biological invasions. Am Nat 146:229-251

Shore R, Hare EJ (2008) Bank vole. In: Harris S, Yalden DW (eds) Mammals of the British Isles: handbook, 4th edn. The Mammal Society Southampton, UK, pp 88-99

Simberloff D, Von Holle B (1999) Positive interactions of nonindigenous species: invasional meltdown? Biol Invasions 1:21-32

Skellam JG (1951) Random dispersal in theoretical populations. Biometrika 38:196-218

Smal CM, Fairley JS (1978) The spread of the bank vole since 1970. Irish Nat J 19:237-239

Smal CM, Fairley JS (1984) The spread of the bank vole Clethrionomys glareolus in Ireland. Mammal Rev 14:71-78

Smiddy P, Sleeman DP (1994) The bank vole in County Cork. Irish Nat J 24:360-364

Smith JE, Batzli GO (2006) Dispersal and mortality of prairie voles (Microtus ochrogaster) in fragmented landscapes: a field experiment. Oikos 112:209-217

Stenseth NC, Gustafsson TO (1985) Reproductive rates, survival, dispersal and cyclicity in Clethrionomys species: some theoretical considerations. Ann Zool Fenn 22:289-301

Stuart P, Mirmin L, Cross TF et al (2007) The origin of Irish bank voles Clethrionomys glareolus assessed by mitochondrial DNA analysis. Irish Nat J 28:440-446

Tosh DG, Lusby J, Montgomery WI et al (2008) First record of greater white-toothed shrew Crocidura russula in Ireland. Mammal Rev 38:321-326

Urban MC, Phillips BL, Skelly DK et al (2008) A toad more travelled: the heterogeneous invasion dynamics of cane toads in Australia. Am Nat 171:134-148

Waser PM (1985) Does competition drive dispersal? Ecology 66:1170-1175

Williamson M (1996) Biological invasions. Chapman \& Hall, London

Wilson RJ, Davies ZG, Thomas CD (2009) Modelling the effect of habitat fragmentation on range expansion in a butterfly. Proc R Soc B 276:1421-1427

With KA (2002) The landscape ecology of invasive spread. Cons Biol 16:1192-1203

Ylönen H (1988) Diel activity and demography in an enclosed population of the vole Clethrionomys glareolus (Schreb). Ann Zool Fenn 25:221-228

Ylönen H, Mappes T (1995) Spacing behavior and key resources: an experiment on seasonal preference of male bank voles, Clethrionomys glareolus, for food and females. Ann Zool Fenn 32:445-448 